\title{
Characterization and selection of waste oils for the absorption and biodegradation of VOC of different hydrophobicities
}

Margaux Lhuissier ${ }^{\mathrm{a}}$, Annabelle Couvert ${ }^{\mathrm{a}}$, Abdeltif Amrane ${ }^{\mathrm{a}, \mathrm{b}}$, Abdoulaye Kane ${ }^{\mathrm{a}, \mathrm{c}}$, Jean-Luc Audic $^{\mathrm{a}, \mathrm{b}}$

a Ecole Nationale Supérieure de Chimie de Rennes, CNRS, UMR 6226, 11 Allée de Beaulieu, CS 50837, 35708 Rennes Cedex 7, France

b Université de Rennes 1, Institut des Sciences Chimiques de Rennes (UMR 6226), 263 avenue du Général Leclerc, 35042 Rennes, France

c Ecole des Métiers de l'Environnement (EME), Campus de Ker Lann, avenue Robert Schuman, 35170 Bruz, France

Graphical abstract

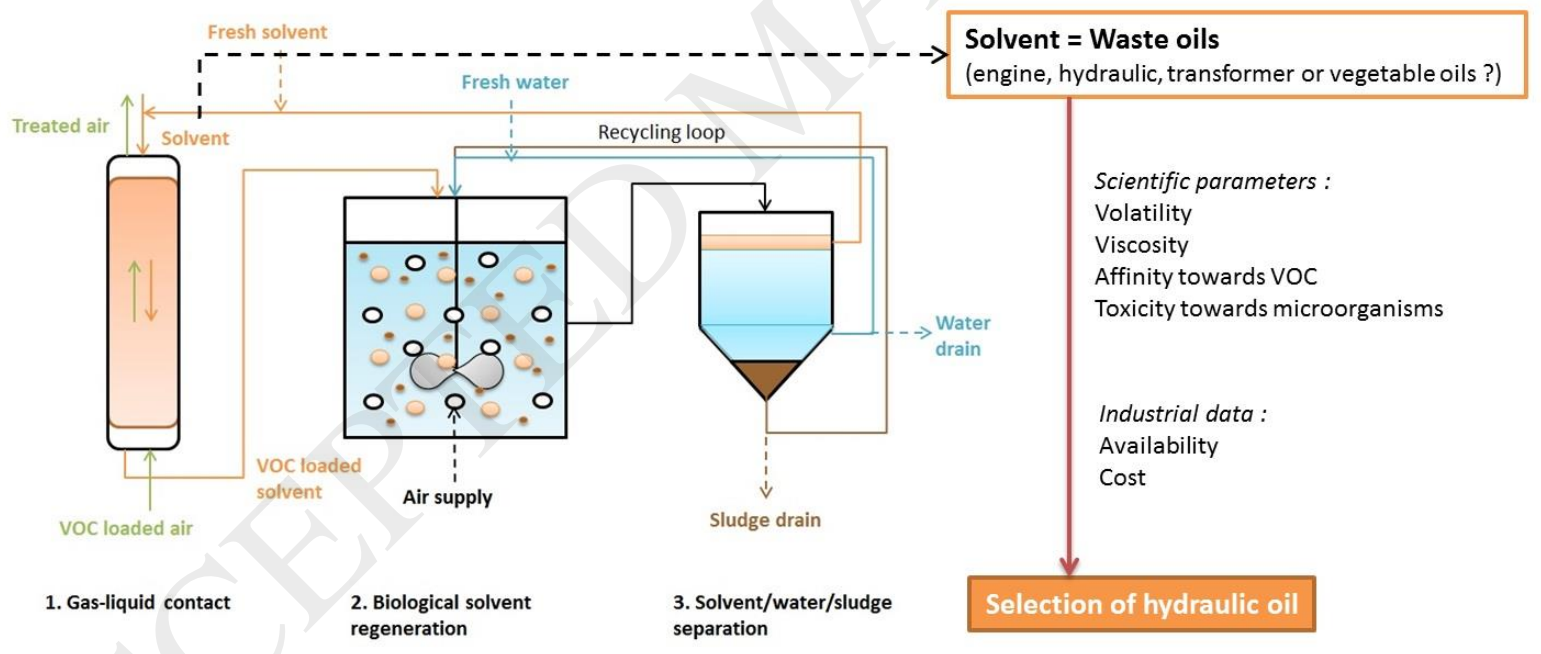

Highlights

- Waste oils have been studied as a solvent for absorption and biodegradation of 7 VOC

- Volatility, viscosity, partition coefficient and toxicity towards VOC were investigated 
- Choice of a solvent depends also on its availability and cost

- Engine oil is not appropriate to absorption of VOC because of its high volatility

- Hydraulic oil is the most suitable waste oil for absorption and biodegradation of VOC

\section{Abstract}

The purpose of this study was to test different kinds of industrial waste oils to be implemented as Non-Aqueous-Phase for Volatile Organic Compounds absorption and degradation in a process coupling a packed column and a Two-Phase Partitioning Bioreactor. Engine, hydraulic, transformer and vegetable oils were tested. The VOC targeted were: $n$-heptane, ethyl acetate, isopropanol, methylisobutylketone, toluene, $m$-xylene and 1,3,5-trimethylbenzene. Several parameters were determined: volatility, viscosity, VOC partition coefficients and toxicity. Results allowed to conclude that hydraulic, transformer and vegetable oils are technically appropriate for the process. According to availability and cost data of waste oils, hydraulic oil was selected.

\section{Introduction}

VOC are defined by the European VOC solvents Directive 1999/13/EC as compounds with a vapor pressure above $10 \mathrm{~Pa}$ at $20^{\circ} \mathrm{C}$ (“EUR-Lex - 31999L0013 - EN - EUR-Lex," 1999; Le Cloirec, 2004). Their origin are either anthropogenic or from natural sources (mainly emitted from forests (Kim, 2001)). In France, even if anthropogenic VOC emissions show a wide reduction since the 1990s : 74\% from 1990 to 2015 ("COV - CITEPA," 2017), VOC treatment is an important challenge for environmental protection and human health because of hazardous effects of these compounds. First, VOC are involved in global warming by producing tropospheric ozone production which is a greenhouse gas with a global warming potential 2000 times higher than $\mathrm{CO}_{2}$ (Mohseni and Allen, 2000). The ozone is produced by the disruption of the Chapman cycle which normally regulates NOx chemistry in the 
atmosphere: VOC produce more $\mathrm{O}$ radicals which produce more tropospheric ozone. Moreover, ozone produced in the lower stratum of atmosphere is a harmful compound for human respiratory system and the environment (Le Cloirec, 2004). Several VOC are identified to be directly responsible of serious diseases or troubles, the main effects concerning respiratory functions, blood system, liver, and central nervous system. Some VOC show more serious issues, with carcinogenic, mutagen effects and can be toxic for reproduction. For example, benzene causes leukemia and toluene is known to be harmful towards reproduction abilities (Observatoire régional d'île de France, 2007).

Several solutions are possible to treat VOC emissions: adsorption, condensation, thermic or catalytic oxidation, photocatalysis and biotechnologies. $5 \%$ of the current installations for VOC treatment use biological technologies (Le Cloirec, 2004; SOLTYS, 1998). One of the issues of biological processes such as biofiltration, is the poor solubility of hydrophobic VOC in water and so, their poor biodegradation. The introduction in the bioreactor of a NonAqueous-Phase (NAP), with a good affinity with targeted hydrophobic VOC, would enhance the transfer of VOC from air to microorganisms for degradation; such kind of bioreactor is called a Two-Phase Partitioning Bioreactor (TPPB). At high load, the NAP in the TPPB has a buffer capacity. Indeed, the VOC which can be potentially toxic towards microorganisms are mainly located in the NAP, keeping therefore the VOC concentration in the aqueous phase below the toxic limit concentration. NAP also acts as a VOC reservoir for microorganisms during VOC low load periods to insure a sufficient microbial activity (Boudreau and Daugulis, 2006).

The process studied in this work, presented in Figure 1, is a combination of two steps, namely absorption of targeted VOC in a NAP and its biological regeneration in a TPPB (Guillerm et al., 2016a). First, VOC contained in polluted air are transferred in the NAP during an absorption step implemented in a packed column (step 1). Secondly, the VOC loaded NAP is transferred to a TPPB in order to perform VOC degradation, probably aerobic (next studies will determine this parameter), by microorganisms present in the aqueous phase 
(step 2). Once the NAP is unloaded of VOC, it is separated from the aqueous phase, and used for a new cycle returning to the absorption step.

One key parameter of satisfactory functioning of TPPB is the choice of the NAP. To validate a NAP for the process studied, it should comply with the following properties: good affinity with targeted VOC to insure the highest transfer from air to NAP, low volatility to avoid the counter-productive effect of NAP initially loaded with volatile compounds by stripping, reasonable viscosity to insure a reasonable pressure loss, especially in the absorption step, non-toxicity towards microorganisms, no biodegradability to minimize its loss in the system (Darracq et al., 2010; Guillerm et al., 2016a). Among the solvents tested, previous works showed that, for the absorption of toluene, silicone oil was the most suitable NAP, because of its low volatility, its biocompatibility towards microorganisms and its non-biodegradable character and its low partition coefficient of toluene between silicone oil and air (Darracq et al., 2010; Guillerm et al., 2016a).

However, in order to choose a NAP to insure a full-size industrial application, further parameters have to be taken in account. First, most of the time, industrial flow rates of polluted air to be treated are important and involve consequent flow rates of NAP within the framework of absorption in a packed column. Consequently, important volumes of NAP should be available. Secondly, in order to insure the economic efficiency of the process, NAP cost should be affordable.

This study was integrated to an industrial project. The purpose was to treat a mixture of VOC of different natures and hydrophobicities, similar to the real polluted VOC flow composed of alkanes, alcohols, esters, ketones and aromatic compounds. A mixture of seven VOC with different hydrophobicities was chosen to simulate the real mixture during laboratory trials: $n$-heptane, isopropanol, ethyl acetate, methylisobutylketone (MIBK), 
toluene, m-xylene, 1,3,5-tri-methylbenzene. Each one of the molecules was detected on the industrial site.

One of the activities handled in the industrial site is the collection of waste oils such as engine oil, hydraulic oil, vegetable oil and transformer oil. The purpose of this industrial partnership was to valorize such waste oil through their use as NAP instead of silicone oil to absorb VOC from polluted air flow and reduce VOC emission in the atmosphere below the French regulation limit of $110 \mathrm{mg} \cdot \mathrm{m}^{-3}$ in total carbon (TC) ("Arrêté du 2 février 1998 relatif aux prélèvements et à la consommation d'eau ainsi qu'aux émissions de toute nature des installations classées pour la protection de l'environnement soumises à autorisation," 2015). Indeed, waste oils are directly available on the industrial site and widely inexpensive compare to silicone oil (approximately from 30 to 150 times) extensively used in other studies (Aldric and Thonart, 2008; Darracq et al., 2012, 2010; Dumont et al., 2016, 2010; Guillerm et al., 2016b; Patel et al., 2017; Poddar and Sirkar, 1996). Few studies approach VOC absorption by an oil other than silicone oil : some authors (Bourgois et al., 2009; Frédéric Heymes et al., 2006; Vuong et al., 2009) studied toluene absorption in phthalates and adipates, such as di-2-ethylhexylphtalate (DEHP) or di(2-ethylhexul)adipate (DEHA). Polyethylene glycols (PEG) and ionic liquids are also liquid phases investigated for VOC absorption (Cotte et al., 1995; Quijano et al., 2013, 2011; Vuong et al., 2009; Wang et al., 2017, 2001). Vegetable oils are long chained triglycerides extracted from different vegetable sources. Mineral oils are long chained alkanes produced by refining crude oil and are used to lubricate internal engines. Ozturk and Yilmaz (Ozturk and Yilmaz, 2006) worked on benzene, toluene, carbone tetrachloride and methanol absorption in fresh and waste lubricant and vegetable oils and show satisfactory results (70 to $95 \%$ of absorption removal) and toluene absorption in vegetable oil has been studied by Hariz et al. (Hariz et al., 2017). Bay and al. studied benzene, toluene and dichloroethane absorption in biodiesel (Bay et al., 2006) and Lalanne and al. (Lalanne et al., 2008) investigated a mixture of oxygenated, aromatic and halogenated compounds in soluble cutting oil: introduction of oil showed an improvement of 
absorption compared to water for aromatic and halogenated compounds contrary to oxygenated compounds.

In order to treat a mixture of 7 VOC of different hydrophobicities, the objectives of this study were to select one kind of waste oil for their absorption abilities. For this purpose several parameters were analyzed: oil volatility, viscosity, affinity for the targeted VOC and toxicity towards microorganisms involved in the TPPB. In this industrial context, the oil selection should be done in accordance with the availability and the cost of waste oils.

\section{Experimental}

\subsection{Chemical products}

The VOC to be treated were chosen after characterization of polluted atmosphere on the industrial site through several identification screenings. In order to permit laboratory trials, 7 model VOC were chosen to represent the real polluted flow on site: $n$-heptane, ethyl acetate, 2-propanol, methylisobutylketone (MIBK), toluene, m-xylene and 1,3,5-trimethylbenzene.

The waste oils collected on the industrial site are presented in Table 1 with their chemical nature and industrial origin. This is commercial industrial data, and hence no real values can be given, only relative appreciations. The availability of oil in terms of volume is essential to be known to the extent that air treatment involves generally large air flow rates, leading therefore to large flow rates of oil for VOC treatment in a gas-liquid contactor. The added value of the waste oil is linked to its potential selling, an important economic parameter for an industrial company.

\subsection{Volatility measurement}

Waste oils are used in many different applications and additives can be implemented to oils; moreover, waste oils can eventually be in contact with volatile compounds during their use. In this study, volatility of oil is defined as volatile emissions from waste oils, GC-MS analysis showed that these compounds are a complex mixture of VOC. In order to avoid a 
counterproductive effect about VOC elimination by desorption of volatile compounds initially contained in the waste oil, it is necessary to check if the waste oil already releases volatile molecules and quantify these emissions. For this purpose, compressed air was bubbled at fixed flow rate in a waste oil volume of $40 \mathrm{~mL}$; the released air from oil after bubbling was then analyzed by a Photo Ionization Detector (PhoCheck Tiger, lonscience) measuring the total concentration of released molecules. This concentration was measured in ppm isobutylene and then converted into $\mathrm{mg} \cdot \mathrm{m}^{-3}$ in total carbon.

The experiment was then completed at ambient temperature $\left(25^{\circ} \mathrm{C}\right)$. To evaluate the effect of water-washing of oil on its volatility, the results for raw waste oil and waste oil obtained after one water-washing were compared. The water-washing consists of mixing and stirring water and oil (50/50 v/v) for $4 \mathrm{~h}$. The volatility was finally measured in the same way explained above.

\subsection{Viscosity measurement}

The kinematic viscosity of tested waste oils is essential in order to evaluate its ability of use in a gas-liquid contactor. The kinematic viscosity was measured by a capillary viscositymeter (Sevatis, PRO-LABO). In a capillar tube maintained at $40^{\circ} \mathrm{C}$, several drops of oil were dropped off and the falling time of the oil volume along the capillary tube was measured. The kinematic viscosity was deduced with the inherent constant of the instrument. The temperature of $40^{\circ} \mathrm{C}$ was chosen because standard industrial analyses were done at this value and had to be compared with our experimental values.

\subsection{Partition coefficients}

The affinity of the targeted VOC with the different waste oils was evaluated by the partition coefficient measured for each of the 7 targeted VOC in each different oil. The partition coefficient was determined by the static headspace method (Darracq et al., 2010; Guillerm et al., 2016a). In sealed $22 \mathrm{~mL}$ vials, a volume of $0.5 \mathrm{~mL}$ of waste oil $\mathrm{V}_{\text {oil }}$ and a volume of $0.2,0.5,1.0,1.5$ and $2 \mu \mathrm{L}$ of liquid $\mathrm{VOC} \mathrm{V}_{\mathrm{vOC}}$ were inserted. The vials were stirred 
and kept at a constant temperature of $25^{\circ} \mathrm{C}$ for $48 \mathrm{~h}$ to $72 \mathrm{~h}$, to allow the concentrations in each phase to reach equilibrium between liquid and gas phases. Once, the equilibrium was reached, the concentration of VOC in the gas phase $\left(\mathrm{C}_{G}\right)$ was then measured by gas chromatography (GC Focus, FID) operating under the following conditions : oven temperature at $40^{\circ} \mathrm{C}$, injector temperature $125^{\circ} \mathrm{C}$, FID temperature $190^{\circ} \mathrm{C}$, carrier gas pressure at $2.5 \mathrm{kPa}$. Using a mass balance, the partition coefficient is deduced by Eqs. (1) and (2):

$$
C_{L}=\frac{C_{G} \cdot V_{\text {air,vial }}-V_{\text {CoV } \text {,injected }} \cdot \rho_{C O V}}{V_{\text {oil }, \text { vial }}}
$$

$H=C_{G} / C_{L}(2)$

where $\mathrm{H}$ represents the dimensionless gas-to-liquid concentration ratio.

A dimensional form of the partition coefficient in $\mathrm{Pa} \cdot \mathrm{m}^{3} \cdot \mathrm{mol}^{-1}$ could be calculated using Eq. (3):

$$
H^{\prime}=H \cdot R \cdot T(3)
$$

where $\mathrm{R}$ is the ideal gas constant $\left(8.314 \mathrm{~Pa} \cdot \mathrm{m}^{3} \cdot \mathrm{mol}^{-1} \cdot \mathrm{K}^{-1}\right)$ and $\mathrm{T}$ the temperature $(\mathrm{K})$ (Guillerm et al., 2016a; Patel et al., 2017).

All results were obtained in triplicate and for each combination (VOC, waste oil).

\subsection{Toxicity tests}

The compatibility between waste oils and activated sludge involved in the TPPB is essential to insure the regeneration of used waste oils. Glucose is an easily biodegradable substrate by activated sludge, and hence the purpose of this method was to observe the waste oil effect and so its toxicity on glucose degradation by monitoring its concentration. Glucose degradation was monitored on flasks containing a total liquid volume of $50 \mathrm{~mL}$ with $25 \% \mathrm{v} / \mathrm{v}$ of waste oil and $75 \% \mathrm{v} / \mathrm{v}$ of an aqueous phase composed of an initial concentration of glucose of $2 \mathrm{~g} \cdot \mathrm{L}^{-1}$, an activated sludge inoculum concentration of $0.5 \mathrm{~g} \cdot \mathrm{L}^{-1}$ and a solution of 
nutrients $\left(\mathrm{NH}_{4} \mathrm{Cl} 5.5 \mathrm{~g} . \mathrm{L}^{-1}, \mathrm{KH}_{2} \mathrm{PO}_{4} 3.4 \mathrm{~g} \cdot \mathrm{L}^{-1}, \mathrm{NaH}_{2} \mathrm{PO}_{4}, \mathrm{H}_{2} \mathrm{O} 3.55 \mathrm{~g} . \mathrm{L}^{-1}, \mathrm{MgSO}_{4}, 7 \mathrm{H}_{2} \mathrm{O} 0.25 \mathrm{~g} . \mathrm{L}^{-}\right.$

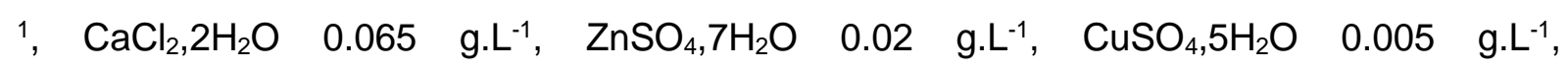
$\left.\left(\mathrm{NH}_{4}\right)_{6} \mathrm{Mo}_{7} \mathrm{O}_{24}, 6 \mathrm{H}_{2} \mathrm{O} 0.0035 \mathrm{~g} \cdot \mathrm{L}^{-1},\left(\mathrm{NH}_{4}\right)_{2} \mathrm{Fe}\left(\mathrm{SO}_{4}\right)_{2}, 6 \mathrm{H}_{2} \mathrm{O} 0.14 \mathrm{~g} \cdot \mathrm{L}^{-1}\right)$. Experiments were made in duplicate. The reference was only composed of the aqueous phase, without any waste oil.

The analysis of the glucose concentration is based on two enzymatic reactions with peroxidase (POD) and a glucose oxidase (GOD) associated with a chromogenic compound 2,2'-azino-bis(3-ethylbenzothiazoline-6-sulphonic acid (ABTS). Each sample is introduced in a UV cell, and then GOD, POD, ABTS solutions are added. After a reaction time of around $30 \mathrm{~min}$ at ambient temperature $\left(25^{\circ} \mathrm{C}\right)$, mixtures are analyzed by UV spectrophotometer at $420 \mathrm{~nm}$.

\section{Results and Discussion}

\subsection{Volatility}

An excessive volatility of waste oil would be counterproductive towards VOC absorption performance. Indeed, in the packed column (step 1) the VOC initially contained in waste oils could be stripped by the gas stream, leading to an increase of VOC outlet concentration and so an inefficient air treatment. Waste oils contain many different volatile elements after their use in various industries, especially because of additives or mixing with others liquids or solvents (Ozturk and Yilmaz, 2006). To permit an optimal use of mineral oil in processes as lubricant or engine oil, for instance in case of very low temperatures, several additives are added: oxidation inhibitors, detergent dispersants, corrosion inhibitors, rust inhibitors, antifoaming agent, anti-wear agent (Ozturk and Yilmaz, 2006). If these compounds are volatile, it could represent a secondary source of VOC emissions, reducing significantly the efficiency of absorption process.

Figure 2 shows the volatility measurement results for the waste oils tested. 
Engine oil has a volatility value widely above the regulation limit even after one waterwashing so it appeared not appropriate for implementation in the process, especially for absorption (step 1), and hence was discarded. The other oils have moderately low volatility and are compatible with the absorption step for this parameter. Otherwise, vegetable oils (4 samples) have more stable volatility values compared to hydraulic (10 samples) or transformer oils ( 4 samples), as illustrated by the low error bars for this oil compared to the others. This may be due to its single way of use: frying in food industry which involve generally the same process, while hydraulic and transformer oils could be used in different applications and in different kinds of industry involving different additives more or less volatile (Ozturk and Yilmaz, 2006). These results are consistent with the study of Bay and al. (Bay et al., 2006), which showed that biodiesel used in engine emits considerable amounts of VOC described as byproducts, residual reactants, free acids and glycerides, which are not compatible with air treatment in an absorption reactor.

The volatility decrease after water-washing varied widely according to the kind of waste oils and even the sample. Oil washing cannot guarantee a reduction of volatility, especially for hydraulic and transformer oils and cannot be a reliable pre-treatment process before the use of waste oil in the proposed process. Other processes will be investigated in a future study to reduce efficiently volatility in waste oils.

\subsection{Kinematic viscosity}

Oil viscosity is a key parameter for the considered process; it affects both process steps: absorption (step 1) by influencing pressure drop and mass transfer through diffusivity values (Guillerm et al., 2016b; Hariz et al., 2017; Ozturk and Yilmaz, 2006), and also biodegradation in TPPB (step 2) by impacting VOC mass transfer between oil and the degrading biomass (Frederic Heymes et al., 2006). High viscosities lead to high pressure drop, lower diffusivity values which affect mass transfer on the two steps of the process. Viscosity values and its variations should be therefore anticipated. 
Figure 3 shows the kinematic viscosity results for the 4 different waste oil candidates. Transformer oil viscosity is very stable; vegetable oil also shows stable viscosity values contrary to hydraulic oil which displays very variable viscosities. Engine oil kinematic viscosity is the highest one and may cause issues regarding absorption in a packed column (step 1) (pressure drop, reduction of mass transfer) (Guillerm et al., 2016b). Otherwise, the kinematic viscosity values are from the same order of magnitude than the ones used for absorption in the literature. For example, Guillerm et al. used silicon oils between 5.4 and 52 cSt approximately (Guillerm et al., 2016b), Vuong et al. different liquid phases (DEHA, nhexadecane, oleyl alcohol, PEG 400) from 2.7 to 118 cSt approximately (Vuong et al., 2009).

Finally, viscosity is not a clearly selecting parameter but the measured values show the stability character of each kind of oil. Indeed, hydraulic oil has a wide variability among all the different samples tested whereas vegetable oil shows very stable values for several samples. In the extent of a full-scale process involving large volumes of oil, it seems easier to use waste oil with stable properties.

\subsection{Partition coefficient}

Partition coefficient is an essential parameter because it informs about the affinity between a VOC and the waste oil, this parameter has an important impact on absorption performance (step 1) and will determine the dimensions of the packed column (diameter and height), the operational parameters (liquid and gas flow rates, pressure drop) and also the consumption of oil and its regeneration rate; the higher the affinity between the waste oil and the VOC, the higher the capacity of absorption of the waste oil and the lower the frequency of needed regeneration. The results of partition coefficient measurements for the 7 targeted VOC and the 4 waste oils tested and their comparison to silicone oil (Patel et al., 2017) are displayed in Figure 4. As a reminder, a low partition coefficient means a good affinity of a VOC for the considered oil. 
First, in comparison with silicon oil results (Patel et al., 2017) commonly used for absorption studies, waste oils show better capacity for all VOC absorption. Monoaromatic compounds (toluene, $m$-xylene and 1,3,5-trimethylbenzene) are the most efficiently absorbed; while isopropanol and ethyl acetate, the most hydrophilic compounds, are logically the less absorbed. Intermediary absorption values were found for MIBK and $n$-heptane. According to previous studies (Biard et al., 2016; Ito et al., 2008; Ozturk and Yilmaz, 2006, 2006), absorption performance depends on mutual polarities of VOC and liquids and on VOC molecular size. Consequently, as the tested waste oils were composed of highly apolar longchained alkanes, the lower the polarity of VOC the higher the absorption performance. Due to the presence of oxygen atoms of triglycerides in its composition, vegetable oil is slightly more polar (Ozturk and Yilmaz, 2006), but no significant difference in partition coefficient values was noticed in the present work.

It can also be noticed that the 4 waste oils tested in static absorption show roughly the same absorption capacity for a given VOC. Consequently, the partition coefficient cannot be considered as a selecting parameter to select a kind of waste oil for implementation in the considered process.

\subsection{Toxicity and biodegradation}

It is essential, in order to permit the biological regeneration of the oil in a TPPB (step 2), to insure that the selected waste oil is not toxic for biomass to allow the degradation of the previously absorbed VOC (step 1). A potential toxic effect on biomass (activated sludge) was studied by glucose degradation in flasks with or without waste. The results are presented in Figure 5.

For the different waste oils tested, glucose is degraded in less than $30 \mathrm{~h}$. On the one hand, no significant difference between the various oils can be noticed, and on the other 
hand glucose degradation is as fast as in the reference flask without oil. Then, none of the waste oils tested is toxic towards the activated sludge contained in the TPPB. Consequently, waste oils are compatible NAP for implementation in a TPPB (step 2) and with its biological regeneration using activated sludge as degrading biomass. These conclusions are consistent with Liu and Wu study (Liu and Wu, 2006) which showed that $n$-hexadecane is compatible with microorganisms, as well as the study of Raz and Livne (Raz and Livne, 1973) demonstrating that linoleic and oleic acids, which are present in vegetable oil, are also compatible with microorganisms. This result permit the future study of the second step of the proposed process: biological regeneration of VOC loaded waste oil.

\subsection{Selection of the most appropriate waste oil}

The study of the physical and chemical parameters permitted to exclude engine oil for implementation in the process studied because of its high volatility, higher than the guide limit of $110 \mathrm{mg} \cdot \mathrm{m}^{-3} \mathrm{TC}$, leading potentially to secondary VOC emissions and so inefficient air treatment. The choice of a given waste oil as part of an industrial project depends also on the economic data and the availability of the collected waste oils on site. Indeed, a full-scale VOC treatment process adapted to high flow rates and low VOC concentrations involve large volume of absorbent liquids. Table 2 present advantages and disadvantages for each kind of waste oil tested.

The expressions in bold letters are the eliminatory criteria. As a result, vegetable and transformer oils are excluded because of its high cost and its low volume available for the former and its difficulty of supply on site for the latter.

Consequently, according to the physical and chemical characteristics needed for implementation in the proposed process on the one hand and to the industrial constraints on the other hand, only hydraulic oil complied with all the required characteristics and hence was selected. However, further tests should be achieved with hydraulic oil to confirm its suitability for implementation in the proposed process, namely dynamic absorption, 
biodegradation of VOC in a TPPB for its regeneration and finally application at pilot-scale on the industrial site.

\section{Conclusion}

In order to choose a waste oil to be introduced in a process coupling a packed column for absorption of VOC and a TPPB for its degradation, several parameters were measured for different kinds of waste oils collected on the industrial site.

First, volatility tests conducted on the 4 candidate oils showed that engine oil is not an appropriate NAP for implementation in the process because of its high volatility which is widely above the French regulation limit; its use would have a counterproductive effect on absorption performance (step 1). Vegetable, hydraulic and transformer oils had lower volatility values but vegetable oil showed very stable values contrary to hydraulic and transformer oils. These important variations of volatility could be the consequence of either additives to enhance the performances of oil or the consequence of mixing with other solvents before oil collection. Water-washing is not a reliable pre-treatment to remove volatility from oils before their use in the absorption step since the reduction of volatility was very variable; VOC contained in oil seem to be very diversified and not only water-soluble.

Regarding kinematic viscosity, vegetable and transformer oils presented stable values, around $42 \mathrm{cSt}$ and $10 \mathrm{cSt}$ respectively, while hydraulic and transformer oils viscosities varied between 27 and $70 \mathrm{cSt}$; these variations could be the consequence of additives brought to the oil during their use.

All collected waste oils had the same chemical affinity towards the targeted VOC; their performances in terms of partition coefficients between air and oil were better than the values obtained with silicone oil, widely studied in the literature. The monoaromatic compounds such as 1,3,5-trimethylbenzene, $m$-xylene and toluene were the most efficiently absorbed with very low partition coefficients; while hydrophilic compounds such as isopropanol and ethyl acetate were poorly absorbed with higher partition coefficient values. The differences in 
absorption performances between VOC of different hydrophobicities can be explained by their polarities; indeed, owing to the non-polarity of waste oils, the most absorbed VOC are the less polar ones. Partition coefficients obtained with engine, hydraulic, transformer or vegetable oil were nearly similar; the 4 tested oils showed therefore roughly the same absorption performance for the 7 target VOC.

Toxicity of waste oils towards microorganisms involved in the bioreactor for oil regeneration (step 2) was investigated, showing that none of the tested waste oils was toxic towards microorganisms contained in the activated sludge.

Finally, the introduction of industrial data such as availability and cost of waste oils shows that hydraulic oil seems to be the most suitable oil as an NAP for the studied process.

These results permit to consider further trials to confirm the dynamic behavior of hydraulic oil regarding absorption step and on the performances of VOC biodegradation in a TPPB for waste oil regeneration.

\section{Acknowledgements}

The authors would like to thank the French National Association of Research and Technology (ANRT) for their support through a PhD fellowship for M. Lhuissier. 


\section{References}

Aldric, J.-M., Thonart, P., 2008. Performance evaluation of a water/silicone oil two-phase partitioning bioreactor using Rhodococcus erythropolis T902.1 to remove volatile organic compounds from gaseous effluents. J. Chem. Technol. Biotechnol. 83, 14011408.

Arrêté du 2 février 1998 relatif aux prélèvements et à la consommation d'eau ainsi qu'aux émissions de toute nature des installations classées pour la protection de l'environnement soumises à autorisation [WWW Document], 2015. URL https://www.legifrance.gouv.fr/affichTexte.do?cidTexte=LEGITEXT000005625281 (accessed 7.25.17).

Bay, K., Wanko, H., Ulrich, J., 2006. Absorption of Volatile Organic Compounds in Biodiesel. Chem. Eng. Res. Des. 84, 22-28.

Biard, P.-F., Coudon, A., Couvert, A., Giraudet, S., 2016. A simple and timesaving method for the mass-transfer assessment of solvents used in physical absorption. Chem. Eng. J. 290, 302-311. https://doi.org/10.1016/j.cej.2016.01.046

Boudreau, N.G., Daugulis, A.J., 2006. Transient performance of two-phase partitioning bioreactors treating a toluene contaminated gas stream. Biotechnol. Bioeng. 94, 448457.

Bourgois, D., Vanderschuren, J., Thomas, D., 2009. Study of mass transfer of VOCs into viscous solvents in a pilot-scale cables-bundle scrubber. Chem. Eng. J. 145, 446452. https://doi.org/10.1016/j.cej.2008.04.038

Cotte, F., Fanlo, J.L., Cloirec, P.L., Escobar, P., 1995. Absorption of Odorous Molecules in Aqueous Solutions of Polyethylene Glycol. Environ. Technol. 16, 127-136. https://doi.org/10.1080/09593331608616253

COV - CITEPA [WWW Document], 2017. URL https://www.citepa.org/fr/air-etclimat/polluants/aep-item/composes-organiques-volatils (accessed 6.13.17).

Darracq, G., Couvert, A., Couriol, C., Amrane, A., Thomas, D., Dumont, E., Andres, Y., Le Cloirec, P., 2010. Silicone oil: An effective absorbent for the removal of hydrophobic volatile organic compounds. J. Chem. Technol. Biotechnol. 85, 309-313.

Darracq, G., Couvert, A., Couriol, C., Thomas, D., Amrane, A., Dumont, E., Andres, Y., Le Cloirec, P., 2012. Optimization of the volume fraction of the NAPL, silicone oil, and biodegradation kinetics of toluene and DMDS in a TPPB. Int. Biodeterior. Biodegrad. 71, 9-14.

Dumont, E., Couvert, A., Amrane, A., Couriol, C., Darracq, G., Le Cloirec, P., 2016. Equivalent Absorption Capacity (EAC) concept applied to the absorption of hydrophobic VOCs in a water/PDMS mixture. Chem. Eng. J. 287, 205-216. https://doi.org/10.1016/j.cej.2015.11.020

Dumont, E., Darracq, G., Couvert, A., Couriol, C., Amrane, A., Thomas, D., Andrès, Y., Le Cloirec, P., 2010. Determination of partition coefficients of three volatile organic compounds (dimethylsulphide, dimethyldisulphide and toluene) in water/silicone oil mixtures. Chem. Eng. J. 162, 927-934.

EUR-Lex - 31999L0013 - EN - EUR-Lex [WWW Document], 1999. URL http://eurlex.europa.eu/legal-content/EN/TXT/?uri=celex\%3A31999L0013 (accessed 10.6.17).

Guillerm, M., Couvert, A., Amrane, A., Dumont, É., Norrant, E., Lesage, N., Juery, C., 2016a. Characterization and selection of PDMS solvents for the absorption and biodegradation of hydrophobic VOCs: PDMS solvents for absorption and biodegradation of hydrophobic VOCs. J. Chem. Technol. Biotechnol. 91, 1923-1927.

Guillerm, M., Couvert, A., Amrane, A., Norrant, E., Lesage, N., Dumont, E., 2016b. Absorption of toluene in silicone oil: Effect of the solvent viscosity on hydrodynamics and mass transfer. Chem. Eng. Res. Des. 109, 32-40.

Hariz, R., del Rio Sanz, J.I., Mercier, C., Valentin, R., Dietrich, N., Mouloungui, Z., Hébrard, G., 2017. Absorption of toluene by vegetable oil-water emulsion in scrubbing tower: Experiments and modeling. Chem. Eng. Sci. 157, 264-271. 
Heymes, Frederic, Manno Demoustier, P., Charbit, F., Louis Fanlo, J., Moulin, P., 2006. Hydrodynamics and mass transfer in a packed column: Case of toluene absorption with a viscous absorbent. Chem. Eng. Sci. 61, 5094-5106.

Heymes, Frédéric, Manno-Demoustier, P., Charbit, F., Fanlo, J.L., Moulin, P., 2006. A new efficient absorption liquid to treat exhaust air loaded with toluene. Chem. Eng. J. 115, 225-231.

Ito, A., Sui, G., Yamanouchi, N., 2008. VOC vapor permeation through a liquid membrane using triethylene glycols. Desalination 234, 270-277. https://doi.org/10.1016/j.desal.2007.09.094

Kim, J.-C., 2001. Factors controlling natural VOC emissions in a southeastern US pine forest. Atmos. Environ. 35, 3279-3292.

Lalanne, F., Malhautier, L., Roux, J.-C., Fanlo, J.-L., 2008. Absorption of a mixture of volatile organic compounds (VOCs) in aqueous solutions of soluble cutting oil. Bioresour. Technol. 99, 1699-1707.

Le Cloirec, P., 2004. COV (composés organiques volatils). Tech. L'Ingénieur G1, 1-10.

Liu, Y.S., Wu, J.Y., 2006. Use of $n$-hexadecane as an oxygen vector to improve Phaffia rhodozyma growth and carotenoid production in shake-flask cultures. J. Appl. Microbiol. 101, 1033-1038. https://doi.org/10.1111/j.1365-2672.2006.03009.x

Mohseni, M., Allen, D.G., 2000. Biofiltration of mixtures of hydrophilic and hydrophobic volatile organic compounds. Chem. Eng. Sci. 55, 1545-1558.

Observatoire régional d'île de France, 2007. Les composés organiques volatils (COV), Etat des lieux: définition, sources d'émissions, exposition, effets sur la santé.

Ozturk, B., Yilmaz, D., 2006. Absorptive Removal of Volatile Organic Compounds from Flue Gas Streams. Process Saf. Environ. Prot. 84, 391-398.

Patel, M.J., Popat, S.C., Deshusses, M.A., 2017. Determination and correlation of the partition coefficients of 48 volatile organic and environmentally relevant compounds between air and silicone oil. Chem. Eng. J. 310, 72-78.

Poddar, T.K., Sirkar, K.K., 1996. Henry's law constant for selected volatile organic compounds in high-boiling oils. J. Chem. Eng. Data 41, 1329-1332.

Quijano, G., Couvert, A., Amrane, A., Darracq, G., Couriol, C., Le Cloirec, P., Paquin, L., Carrié, D., 2013. Absorption and Biodegradation of Hydrophobic Volatile Organic Compounds in Ionic Liquids. Water. Air. Soil Pollut. 224. https://doi.org/10.1007/s11270-013-1528-y

Quijano, G., Couvert, A., Amrane, A., Darracq, G., Couriol, C., Le Cloirec, P., Paquin, L., Carrié, D., 2011. Potential of ionic liquids for VOC absorption and biodegradation in multiphase systems. Chem. Eng. Sci. 66, 2707-2712. https://doi.org/10.1016/j.ces.2011.01.047

Raz, A., Livne, A., 1973. Differential effects of lipids on the osmotic fragility of erythrocytes. Biochim. Biophys. Acta BBA-Biomembr. 311, 222-229.

SOLTYS, N., 1998. Procédés de traitement des COV ou composés organiques volatils. Tech. L'Ingénieur J3, 1-11.

Vuong, M.-D., Couvert, A., Couriol, C., Amrane, A., Le Cloirec, P., Renner, C., 2009. Determination of the Henry's constant and the mass transfer rate of VOCs in solvents. Chem. Eng. J. 150, 426-430. https://doi.org/10.1016/j.cej.2009.01.027

Wang, W., Ma, X., Grimes, S., Cai, H., Zhang, M., 2017. Study on the absorbability, regeneration characteristics and thermal stability of ionic liquids for VOCs removal. Chem. Eng. J. 328, 353-359. https://doi.org/10.1016/j.cej.2017.06.178

Wang, X., Daniels, R., Baker, R.W., 2001. Recovery of VOCs from high-volume, low-VOCconcentration air streams. AlChE J. 47, 1094-1100. https://doi.org/10.1002/aic.690470516 
Figure 1. Absorption-Biodegradation process with organic phase regeneration for VOC treatment

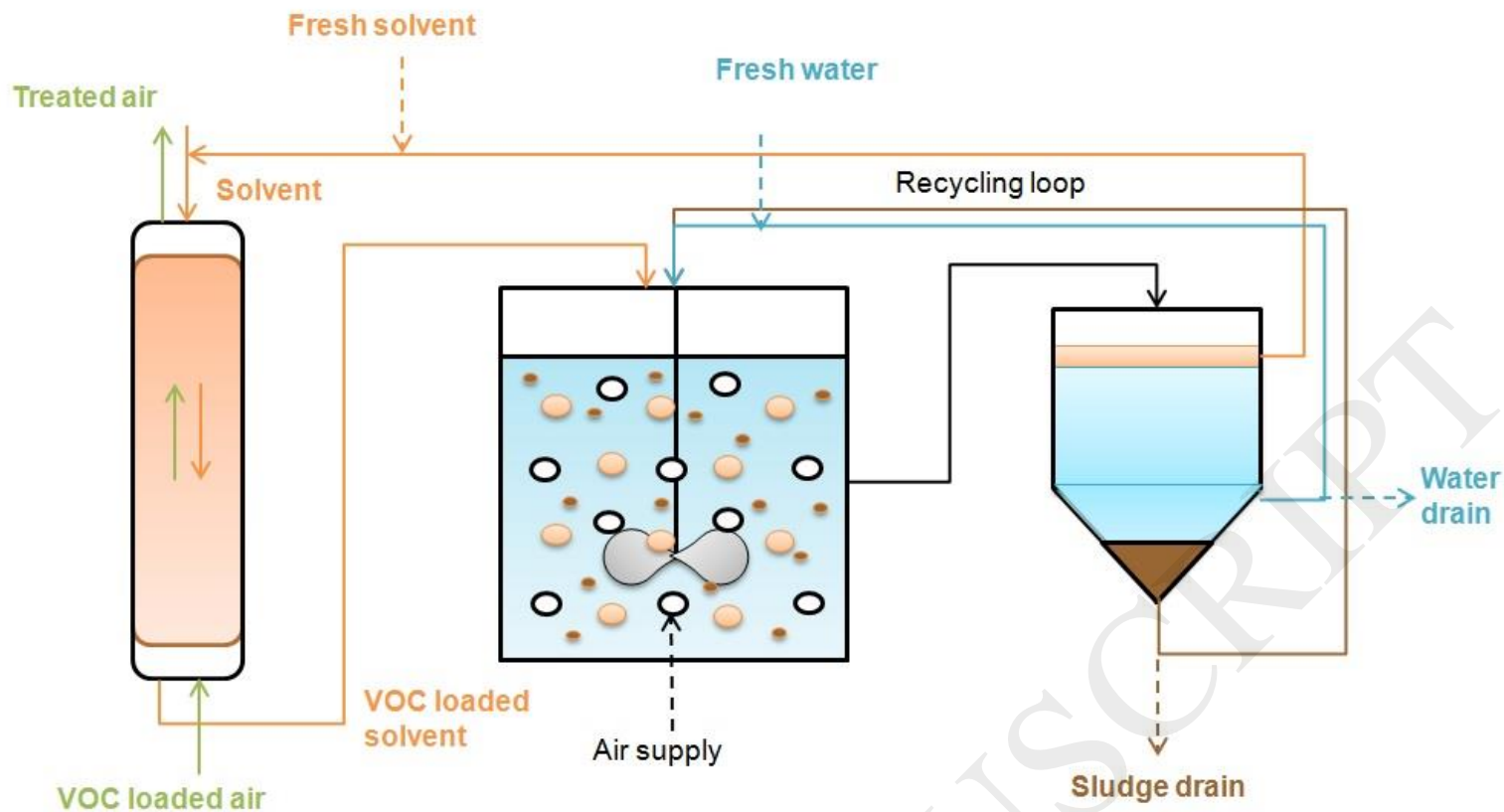

1. Gas-liquid contact

2. Biological solvent regeneration

\section{Solvent/water/sludge separation}

Figure 2. Volatility values for different industrial waste oils

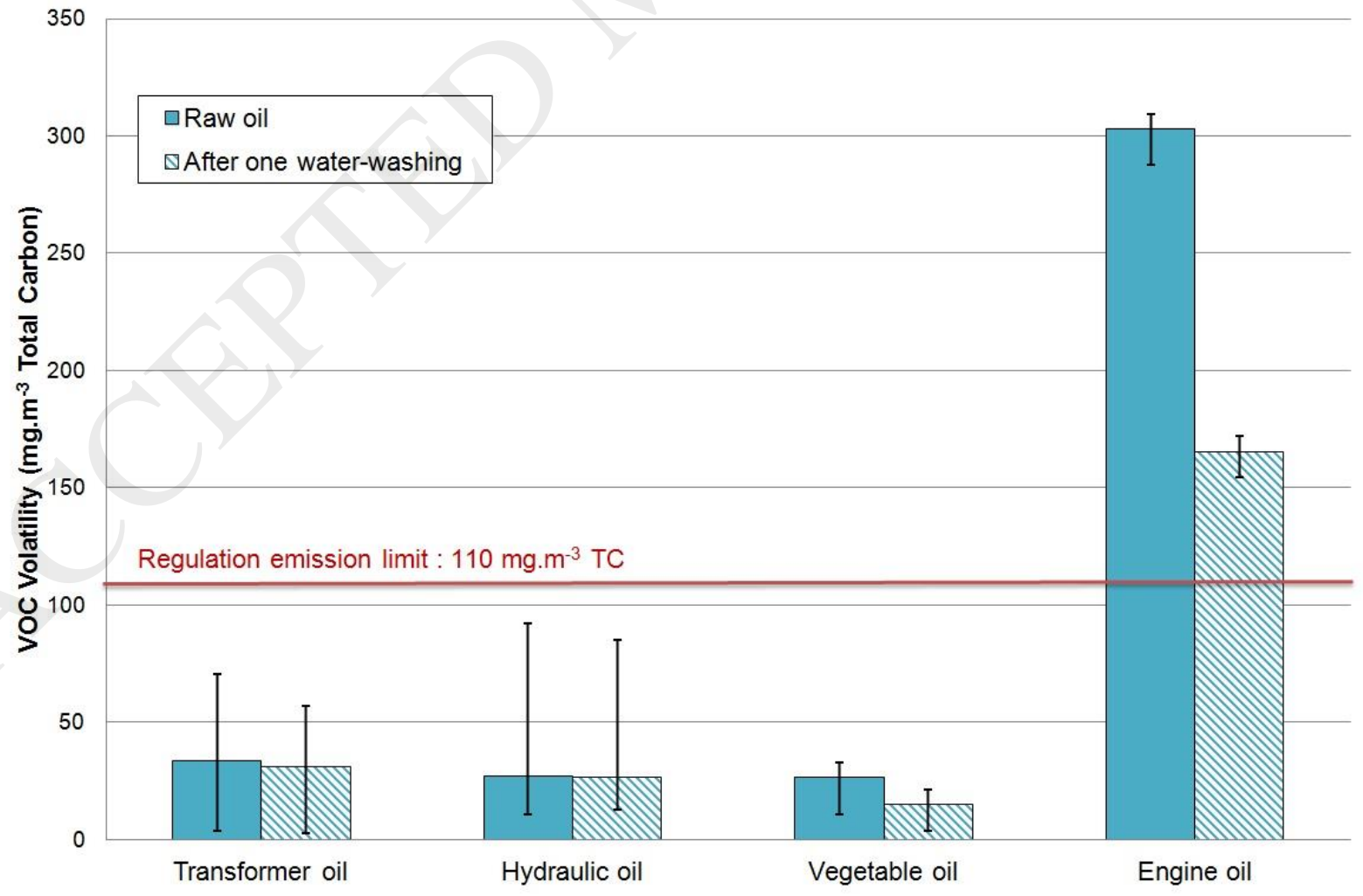


Figure 3. Viscosity values for different industrial waste oils

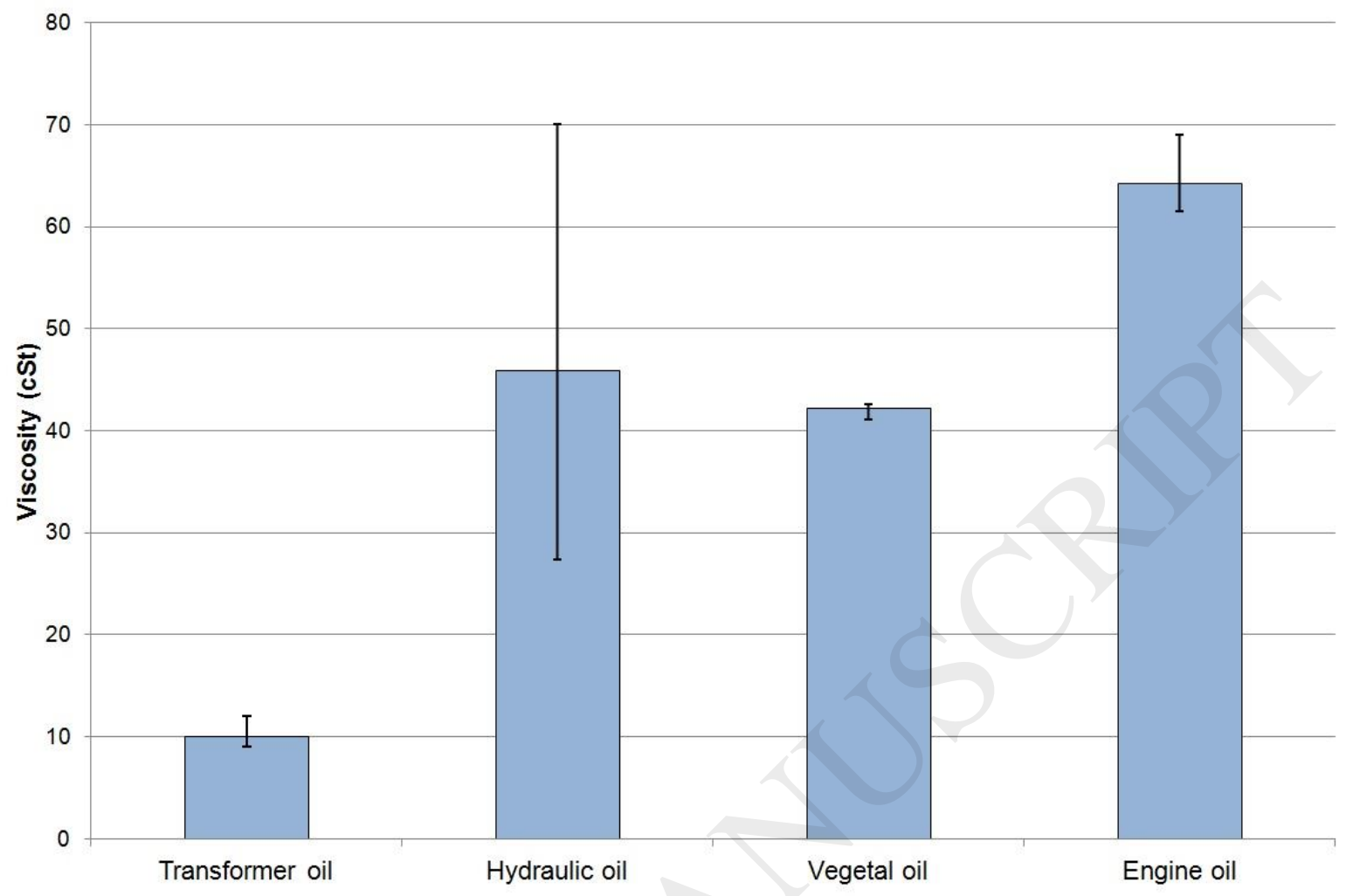

Figure 4. Partition coefficients for different insdutrial waste oils

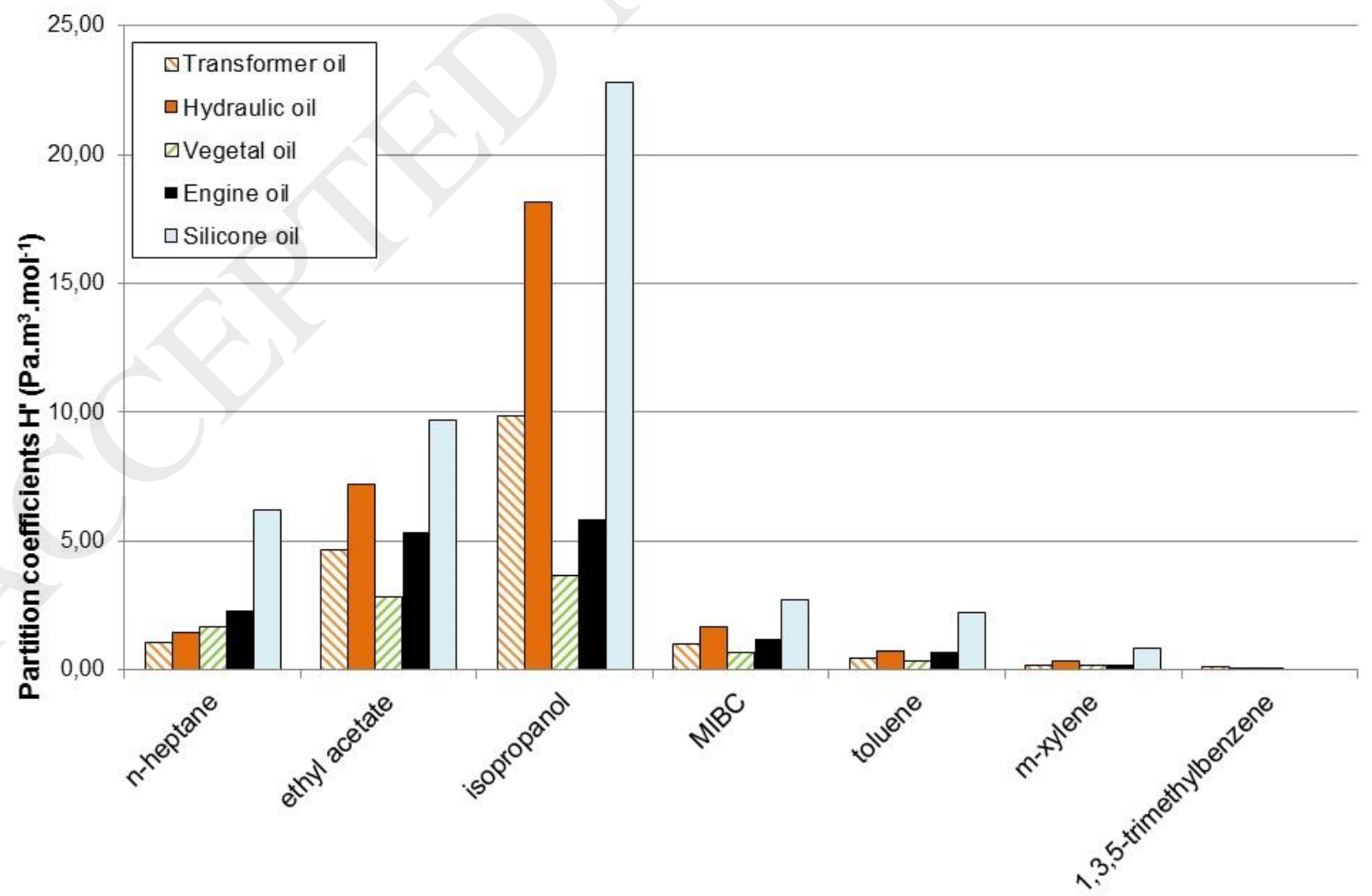


Figure 5. Glucose degradation in TPPB for different waste oils

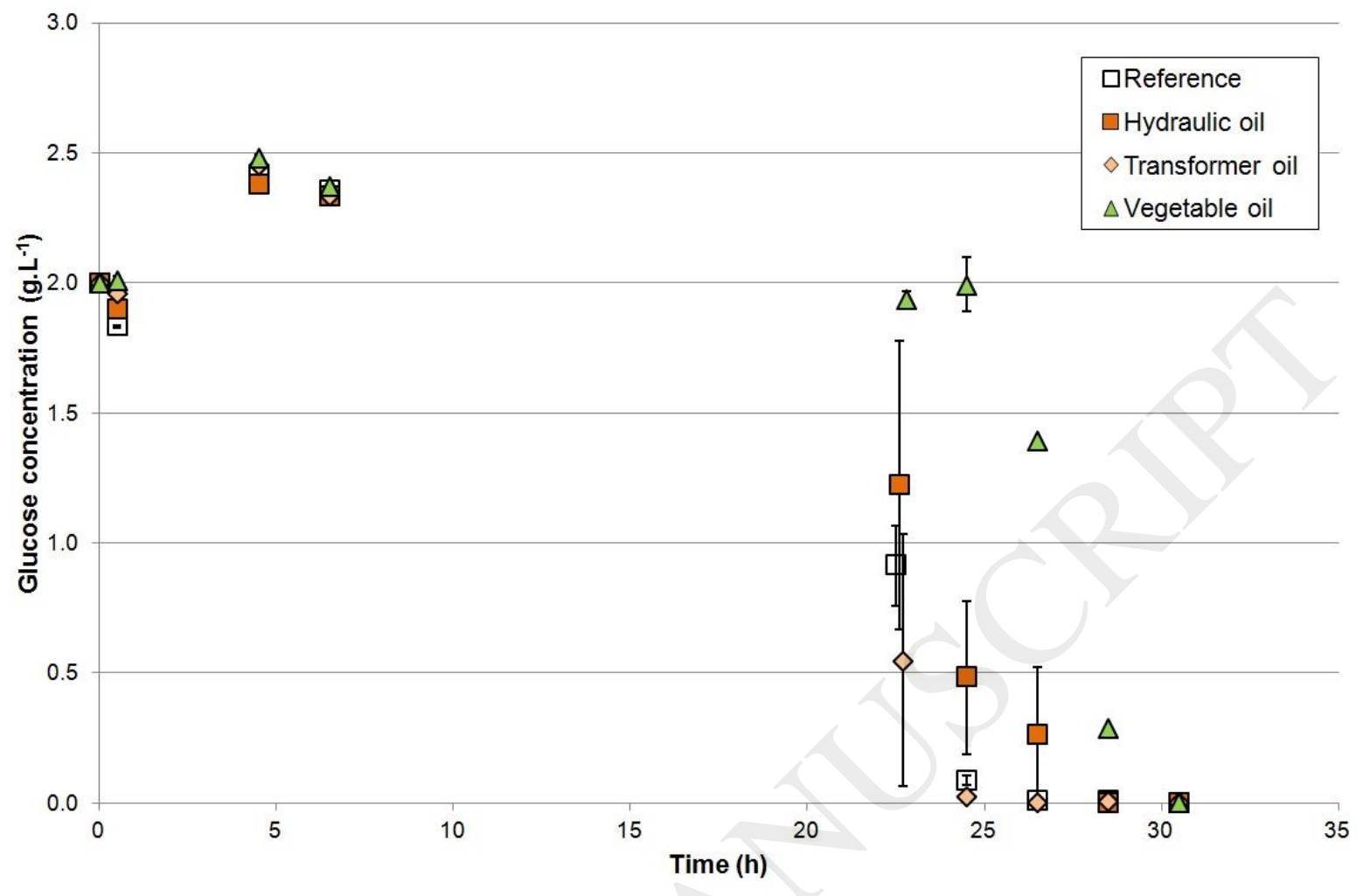


Table 1. Description of the different waste oils tested

\begin{tabular}{|l|l|l|c|c|}
\hline Name & $\begin{array}{l}\text { Chemical } \\
\text { composition }\end{array}$ & $\begin{array}{l}\text { Original industrial } \\
\text { use }\end{array}$ & Availability & Selling value \\
\hline Engine oil & Linear alkanes & Car engines & +++ & -- \\
\hline Hydraulic oil & Linear alkanes & $\begin{array}{l}\text { Hydraulic } \\
\text { function }\end{array}$ & ++ & - \\
\hline Transformer oil & Linear alkanes & Transformers & + & - \\
\hline Vegetable oil & Triglycerides & Food industries & - & ++ \\
\hline
\end{tabular}


Table 2. Advantages and disadvantages of tested waste oils

\begin{tabular}{|c|c|c|}
\hline Kind of oil & Advantages & Disadvantages \\
\hline Engine oil & $\begin{array}{l}\text { Availability }+++ \\
\text { Selling value -- }\end{array}$ & $\begin{array}{l}\text { High volatility : } \mathbf{3 0 0} \mathbf{~} \mathbf{m g} \cdot \mathbf{m}^{-3} \mathbf{T C} \text { approx } \\
\text { High viscosity : } 65 \mathrm{cSt} \text { approx. }\end{array}$ \\
\hline Hydraulic oil & Availability ++ & $\begin{array}{l}\text { Wide volatility range : } 18-92 \mathrm{mg} \cdot \mathrm{m}^{-3} \mathrm{TC} \\
\text { Wide viscosity range }: 27-70 \mathrm{cSt}\end{array}$ \\
\hline Transformer oil & Low viscosity : 10 cSt approx. & $\begin{array}{l}\text { Availability + } \\
\text { Wide volatility range: } 3-70 \mathrm{mg} \cdot \mathrm{m}^{-3} \mathrm{TC}\end{array}$ \\
\hline Vegetable oil & $\begin{array}{l}\text { Narrow viscosity range }: 41-43 \mathrm{cSt} \\
\text { Narrow and low volatility range }: 23-30 \mathrm{mg} \cdot \mathrm{m}^{-3} \mathrm{CT}\end{array}$ & $\begin{array}{l}\text { Selling value ++ } \\
\text { Availability - }\end{array}$ \\
\hline
\end{tabular}

